\title{
A comparative study on the traditional Indian Shodhana and Chinese processing methods for aconite roots by characterization and determination of the major components
}

Yogini Jaiswal ${ }^{1}$, Zhitao Liang ${ }^{1}$, Peng Yong ${ }^{2}$, Hubiao Chen ${ }^{1}$ and Zhongzhen Zhao ${ }^{1 *}$

\begin{abstract}
Background: Aconitum is an indispensable entity of the traditional medicine therapy in Ayurveda and Traditional Chinese medicine (TCM), in spite of its known fatal toxicity characteristics. The prolonged use of this drug, irrespective of its known lethal effects, is governed by the practice of effective detoxification processes that have been used for decades. However, the processing methods of Ayurveda and TCM are different, and no comparative study has been carried out to evaluate their differences.

The objective of the present study was to carry out comparative chemical profiling of the roots of Aconitum heterophyllum Wall, A. carmichaelii Debx., and A. kusnezoffii Reichb. after application of two detoxification methods used in Ayurveda and one method used in TCM .

Results: Analysis of the processed samples was carried out by ultra-high performance liquid chromatography combined with quadrupole time-of-flight mass spectrometry (UHPLC-QTOF/MS). The results obtained in the study demonstrate that all three processing methods used in Ayurveda and TCM effectively extract the diester diterpenoid alkaloids and led to their conversion into monoester diterpenoid alkaloids. The efficiency of the processes in reduction of toxic alkaloid contents can be stated as: Processing with water > Shodhana with cow milk $>$ Shodhana with cow urine. The analysis method was validated as per ICH-Q2R1 guidelines and all the parameters were found to comply with the recommendations stated in the guidelines.
\end{abstract}

Conclusions: There have been no reports till date, to compare the processing methods used in Ayurveda with the methods used in TCM for detoxification of aconite roots. Our study demonstrates that, these methods used in both the traditional systems of medicine, efficiently detoxify the aconite roots. Amongst the three selected procedures, the TCM method of decoction with water is the most efficient. Through experimental evidences, we prove the conversion of toxic diester diterpenoid alkaloids to relatively safer monoester diterpenoid alkaloids. Thus, this study demonstrates that comparative study on the traditional experiences accumulated in different medical systems is useful for expanding their respective applications.

Keywords: Aconitum heterophyllum wall, A. carmichaelii Debx, A. kusnezoffii Reichb, Ranunculaceae, Detoxification, Ayurveda, Traditional Chinese medicine, UHPLC-Q-TOF-MS, Diester diterpenoid alkaloids

\footnotetext{
* Correspondence: zzzhao@hkbu.edu.hk

${ }^{1}$ School of Chinese Medicine, Hong Kong Baptist University, Kowloon, Hong

Kong Special Administrative Region, P. R. China

Full list of author information is available at the end of the article
} 


\section{Background}

For centuries, Aconite has been highly regarded in the traditional medicine of China (TCM) and of India (Ayurveda) $[1,2]$. The genus Aconitum (family Ranunculaceae) has more than 300 species worldwide, of which more than 166 are found in China and India [3,4]. The roots of Aconitum heterophyllum Wall (Atis) are used as medicine in India, and its preparations are mentioned in the Ayurvedic Pharmacopoeia and Ayurvedic formulary of India [5,6]. The processed roots of $A$. carmichaelii Debx. (Zhichuanwu) and A. kusnezoffii (Zhicaowu) have been widely used in China and are listed in the Chinese Pharmacopoeia [7]. These plants are used for treating rheumatalgia, rheumatic arthritis, cold, pain and other ailments [6-11].

As is well known, the unprocessed Aconite root, if ingested, causes fatal toxicities [9-11]. In India and China, many medicinal herbs are subjected to specific treatments before they are used as materia medica. The history of the alchemy of aconite processing in India dates back to the 5th and 6th centuries, and received wide acceptance during the 8th and 9th centuries A.D. After the 8th century the ancient science of pharmacy called "Rasashastra" was used routinely by herbal medical practitioners. Processing methods in Ayurveda (called Samskaras) consist of two stages: The Shodhana (purification or detoxification) and Bhaishajya kalpana (formulation methods). The process of Shodhana involves treatment of the drug with "Goumutra" (cow urine) and cow milk [12-16]. About 200 medical texts that describe the Shodhana process, have been written in various languages. Amongst these 200 published texts, "Charaka Samhita" is said to establish the basic concepts for processing herbal medicines [12-15].

In the ancient TCM records, various methods for detoxification of Aconite roots and 600 different formulations prepared from processed aconite are documented [17]. The use of the processed form of aconitum was first documented in the 'Shennong Materia Medica' (Sheng-nong Ben Cao Jing) written in the Eastern Han Dynasty (24-220 AD); and this herb is an integral part of traditional medicine practices for treatment of arthralgia, colds, cardiac problems, diarrhoea, and oedema [18]. Two classic ancient monographs, namely Lei Gong Processing Handbook (Lei Gong Pao Zhi Lun, written in $500 \mathrm{AD}$ ) and Processing Methodology (Pao Zhi Da Fa, published in 1662), have mentioned the processing method of Aconite roots [19,20]. According to the Chinese pharmacopoeia (2010 edition), various procedures involving treatment with mineral salt water and decoction with water were recorded for processing the roots of A. carmichaelii and A. kusnezoffii to produce the medicinal products called "Fuzi" and "Zhicaowu", respectively $[7,17]$. Among those processing methods, boiling with water for processing the roots of Aconite is the simplest methods and is selected for the present comparative study.

The specific treatments claim to enhance the efficacy and reduce the toxicity of crude drugs by alteration of their pharmacodynamic properties. For Aconite roots, the pharmacodynamic and toxicity level changes occur due to modifications in the structures of Diester Diterpenoid Alkaloids (DDA's) after processing, leading to formation of monoester diterpenoid alkaloids (MDA's) [21-23]. The reaction hypothesised for these changes in the chemistry of Diester Diterpenoid Alkaloids is indicated in Figure $1[17,24]$. There have been several pharmacological studies that demonstrate the reduction in the toxicity of the processed aconitum due to Shodhana treatment $[22,25]$. Although this process has been used for more than 200 years, the alchemy behind these processing strategies still lacks evidence-based scientific validation and needs further understanding. Moreover, there have been no chemical profiling studies that can substantiate and verify the chemical transformations resulting in radical reduction in the toxicity of Aconitum due to Shodhana.

The Shodhana process is not particularly mentioned only for processing of Aconitum heterophyllum in the Ayurvedic Pharmacopoeia of India. There have been no reports published for the quantitation of toxic alkaloids of these three species of Aconitum processed by Shodhana method and for the comparative study of the two traditional processing methods. In contrast, the TCM processes have been explored extensively through pharmacological and analytical studies [8,24-33]. Toxicity of nine types of decoction pieces from the daughter root of A. carmichaelii (Fuzi) based on chemical analysis of diester diterpenoid alkaloids was assessed in our previous study [28].

The aim of the present study was to carry out a comparative study of these two detoxification methods belonging to two different traditional systems of medicine, with a view of providing insights into the changes in the phytochemical composition of the processed forms. The changes were studied with respect to the most toxic components of Aconite viz. aconitine, mesaconitine, and hypaconitine used as markers in the study, as these are the major determinants of aconite toxicity. A ultra-high performance liquid chromatography combined with quadrupole time-of-flight mass spectrometry (UHPLC-Q-TOFMS) method, that has advantages of high sensitivity and mass accuracy over other chromatographic detection methods, was used for the analysis of the samples. The method used was developed and validated as per ICH (Q2-R1) guidelines for validation of analytical methods [34]. 


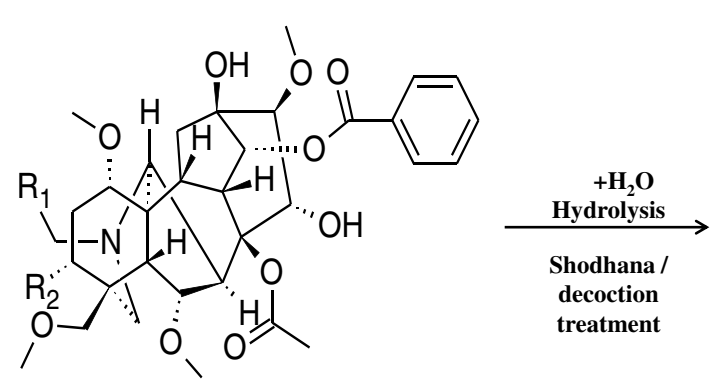

(A)

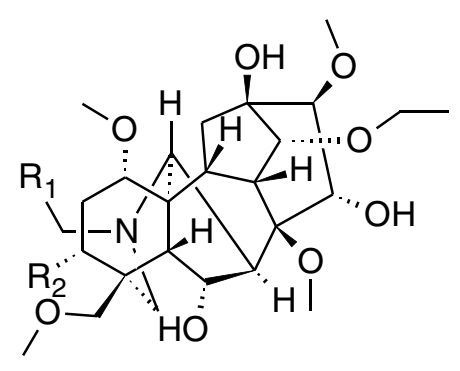

(B)

\begin{tabular}{cccc}
\hline $\mathbf{A}$ & $\mathbf{B}$ & $\mathbf{R}_{\mathbf{1}}$ & $\mathbf{R}_{\mathbf{2}}$ \\
\hline Aconitine & Aconine & $\mathrm{CH}_{2} \mathrm{CH}_{3}$ & $\mathrm{OH}$ \\
Hypaconitine & Hypaconine & $\mathrm{CH}_{3}$ & $\mathrm{H}$ \\
Mesaconitine & Mesaconine & $\mathrm{CH}_{3}$ & $\mathrm{OH}$ \\
\hline
\end{tabular}

Figure 1 Structural changes affected by hydrolysis leading to detoxification of toxic aconitum alkaloids.

\section{Results and discussion}

\section{Validation of the developed analytical method}

The method developed for analyzing the detoxified samples was validated as per ICH guidelines Q2R1. A pictorial representation of the detoxification strategy used is shown in Figure 2, and the LC-MS spectra of marker compounds are shown in Figure 3.

The linearity ranges for all marker compounds were estimated, and satisfactory regression coefficient $\left(r^{2} \geq 0.99\right)$ values were obtained for all three selected markers. The calibration ranges for aconitine $\left(r^{2}=0.9988\right)$, mesaconitine $\left(r^{2}=0.9994\right)$ and hypaconitine $\left(r^{2}=0.9990\right)$ were between $2.0-100 \mathrm{ng} \mathrm{mL}$. The calibration curve equations obtained for all the three markers are shown in Table 1. The limits of detection (LOD) of aconitine, mesaconitine and hypaconitine were found to be $0.383 \mathrm{ng} \mathrm{mL}$, $0.438 \mathrm{ng} \mathrm{mL}^{-1}$ and $0.088 \mathrm{ng} \mathrm{mL}^{-1}$, respectively. The limits of quantitation (LOQ) for aconitine, mesaconitine and hypaconitine were $1.15 \mathrm{ng} \mathrm{mL} L^{-1}, 1.31 \mathrm{ng} \mathrm{mL}^{-1}$ and $0.264 \mathrm{ng} \mathrm{mL}^{-1}$ respectively. All the determinations were carried out with sample concentrations within the calibration range selected for each marker compound. The representative Extracted Compound Chromatogram (ECC) chromatogram, Molecular Feature Extraction (MFE) spectrum, and Total Ion Chromatogram (TIC) overlay spectra of markers along with Base Peak Chromatogram (BPC) of methanol used as solvent are shown in Figure 3.

The precision studies were carried out with three assays, the Interday precision, Intraday precision, and repeatability. The average contents for all markers were calculated for each determination, and the values are indicated in Table 2. All the RSD values are expressed as percentages, and all of them fall within the limits $(\leq 5 \%)$ as stated by the ICH guidelines. For Interday precision, the $\%$ RSD values $(\mathrm{n}=3)$ for aconitine, mesaconitine and hypaconitine were found to be $0.037,0.064$, and 0.107 , respectively. For Intraday precision, the\% RSD values $(\mathrm{n}=5)$ for aconitine, mesaconitine and hypaconitine were $0.243,0.249$ and 0.477 , respectively. The repeatability studies were carried out with 5 replicate determinations of the same samples weighed individually five times. The values of $\%$ RSD $(n=5)$ obtained in repeatability studies for aconitine, mesaconitine and hypaconitine were 0.530 , 0.324 and $0.200 \%$, respectively. The results obtained suggest that the developed method is precise enough to measure the contents in close precision for replicate analysis within the same day, for three consecutive days and for multiple measurements of the same sample on the same day using the optimized chromatographic parameters of the method.

The recovery study for all the three marker compounds was performed at three levels by adding standard compounds at 50, 100 and $150 \%$ of their concentrations in the sample. The results of recovery study are shown in Table 3. Overall, the recoveries were found to be within the range of $85-108 \%$ of the expected concentrations of the standards. Results indicate that the method is accurate and precise enough to recover the compounds of interest from a complex herbal sample matrix. Thus, based upon the results obtained for the validation parameters, we suggest that the validated method can be used for the present study.

The representative LC-MS BPC chromatograms of all the samples indicating the profiles of various components are shown in Figures 4, 5, 6 and Additional file 1: Figures S1, Additional file 2: Figure S2, Additional file 3: 


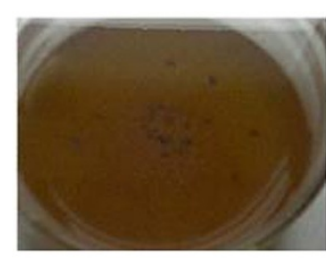

(A)

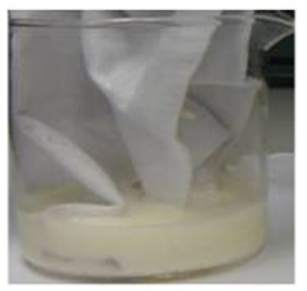

(B)

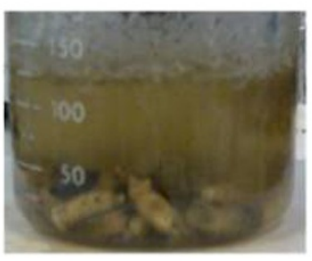

(C)

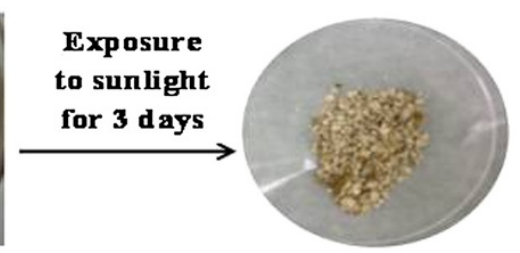

Processed drug

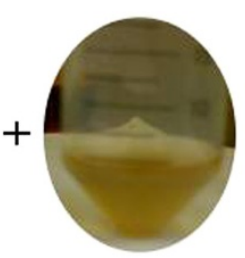

Cow urine filtrate
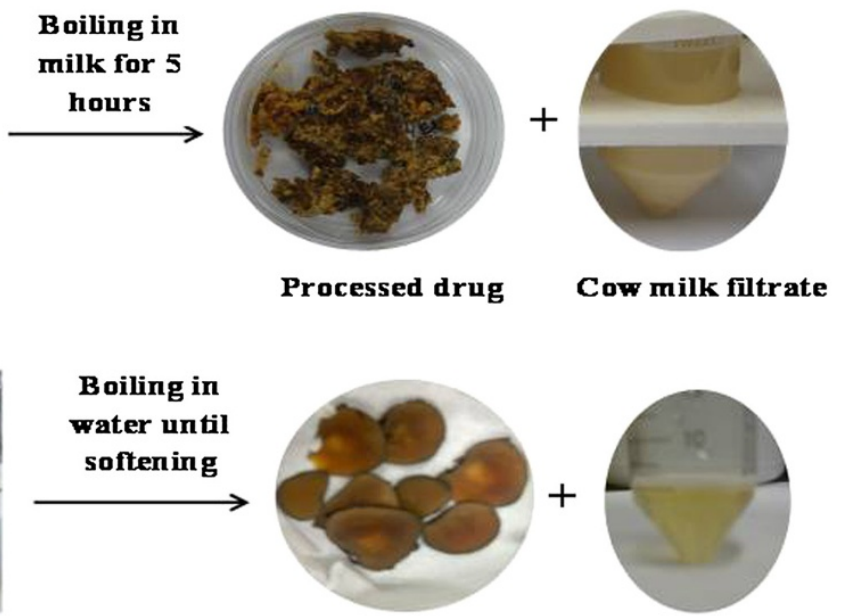

Processed drug Aqueous decoction filtrate

Figure 2 Representation of Shodhana and TCM detoxification process applied for selected Aconitum species (A) Drug treated with cow urine (B) Drug boiled in cow milk (C) Pre-soaked drug subjected to decoction with water.

Figure S3 of the additional data files. Overall 50 constituents in the samples were identified, that included 44 known components and 6 unknown components represented in the additional data files (Additional file 4: Table S1 of additional data file). The marker compounds in samples were estimated by comparing the retention times and mass-to-charge $(\mathrm{m} / \mathrm{z})$ ratios with the reference standards. Aconitine and mesaconitine exhibited retention times of $14.5 \mathrm{~min}$ and $13.5 \mathrm{~min}$ with mass-tocharge $(m / z)$ ratios of 646.322 and 632.306 , respectively. For hypaconitine, the retention time was found to be $14.4 \mathrm{~min}$ with a $\mathrm{m} / \mathrm{z}$ ratio of 616.311 . The other component peaks were identified based upon the $m / z$ values and information available in literature [27,35-37]. To exclude the interferences of the endogenous and exogenous substances that can be present in filtrate of cow urine and cow milk after extraction, the list of components identified in the blank controls with their $\mathrm{m} / \mathrm{z}$ values, retention times, and masses are mentioned in Additional file 5: Table S2 (additional data file).

Reports in literature suggest that the DDA alkaloids upon hydrolysis form MDA compounds. We found similar results in our previous unpublished studies related to metabolite analysis of various Aconitum species [35-37].
This conversion occurs by loss of groups as $\mathrm{BzOH}, \mathrm{H}_{2} \mathrm{O}$, $\mathrm{MeOH}$, and $\mathrm{CO}$. The loss of these chemical group leads to loss in masses of $122 \mathrm{Da}, 18 \mathrm{Da}, 32 \mathrm{Da}$, and $28 \mathrm{Da}$ respectively. The loss of acetic acid group is a characteristic feature for formation of MDA compounds from DDA compounds and results into a loss of $60 \mathrm{Da}$. Through LC-MS analysis, the occurrence of this reaction and formation of MDA compounds can be evidently traced by detection of components with masses similar to the MDA compounds. The MDA compounds formed by molecular changes in DDA compounds are reported in literature, and their $m / z$ values are represented in Additional file 6: Figure S5 (see additional data). In our study we observed the formation of MDA compounds such as benzoyl mesaconine and benzoyl aconine due to hydrolysis reaction during processing. This is evident by the presence of components with masses equal to the reported mass values for these MDA compounds. The LC-MS mass spectra of the filtrates were derived and the formation of hydrolyzed constituents was ascertained. The MDA compounds identified in the processed drugs and the filtrates of mediums used for processing are indicated by suitable abbreviations in LC-MS base peak chromatograms in Figures 4, 5, 6 and ESI scan 


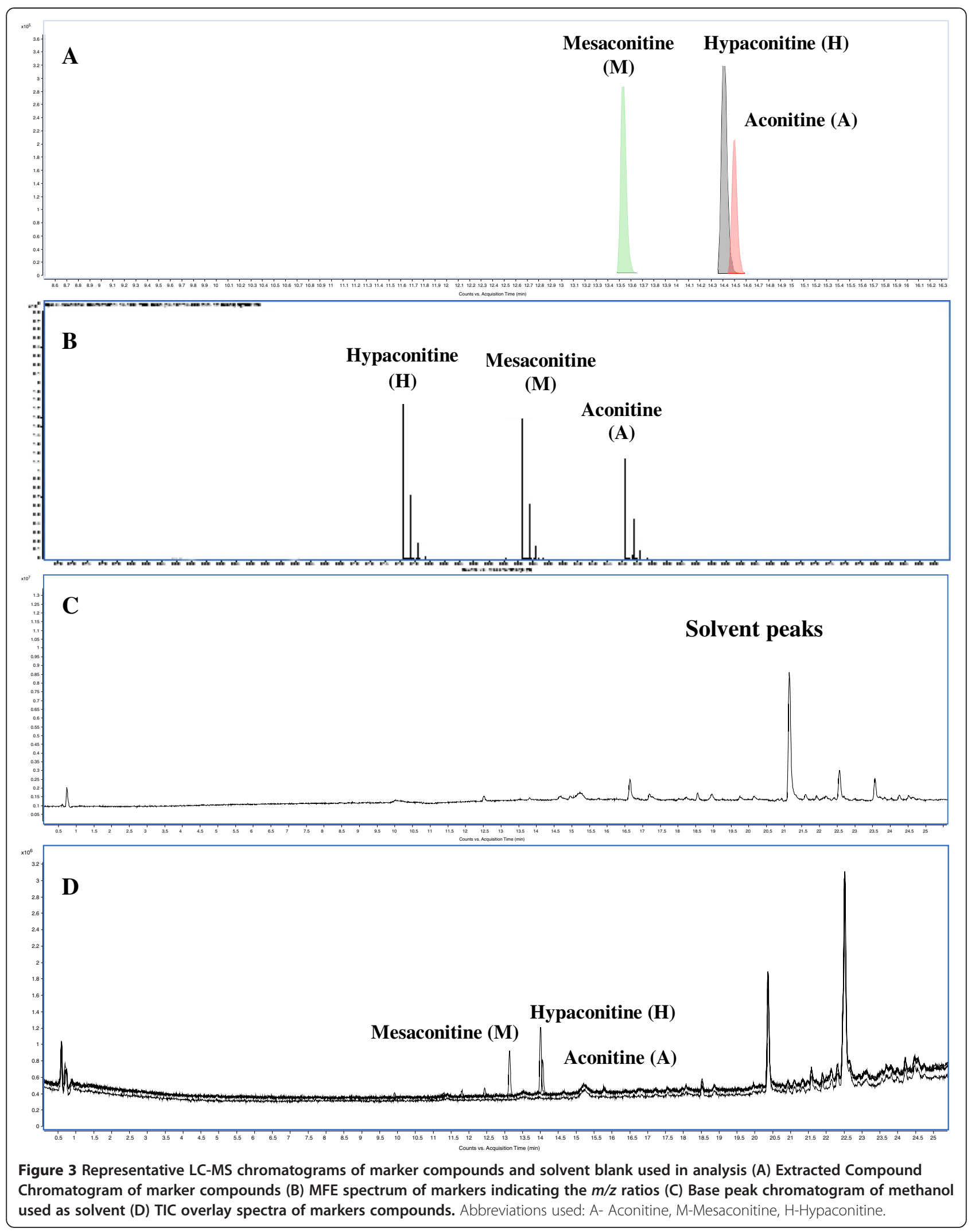


Table 1 Results of linearity studies

\begin{tabular}{lccc}
\hline Parameters & Aconitine & Mesaconitine & Hypaconitine \\
\hline Calibration curve equation & $y=33693.02 x-625.504$ & $y=29797.96 x-51913.504$ & $y=19022.440 x-24159.317$ \\
Correlation coefficient value $\left(\mathrm{r}^{2}\right)$ & 0.9988 & 0.9994 & 0.9990 \\
LOD $\left(\mathrm{ng} \mathrm{mL}{ }^{-1}\right)$ & 0.383 & 0.438 & 0.088 \\
LOQ $\left(\mathrm{ng} \mathrm{mL}{ }^{-1}\right)$ & 1.15 & 1.315 & 0.264 \\
\hline
\end{tabular}

* All the determinations were performed in triplicate at 6 predetermined concentrations.

spectra in Additional file 7: Figure S4, Additional file 6: Figure S5 (additional data) respectively. This provides evidences for the scientific basis of traditional alchemy of detoxification of Aconitum, caused by the hydrolytic conversion of DDA to MDA compounds. To further substantiate the claims of our study, the quantitation of marker alkaloids in the processed and unprocessed drug and the filtrates of various extraction mediums used, was carried out. The estimated contents of the markers in all the samples of each of the three selected species are shown in Table 4. It was observed that, the processing with water extracted the highest amount of marker alkaloids into the solvent filtrate as compared to cow urine and cow milk. The content of aconitine, mesaconitine and hypaconitine in the decoction filtrates was higher than their contents in the processed drug. In the unprocessed drug sample, the content of aconitine, mesaconitine and hypaconitine in A. heterophyllum was lower as compared to A. kusnezoffii and A. carmichaelii.

\section{Comparison of samples treated with cow milk}

The LC-MS chromatogram of A. heterophyllum for unprocessed drug (Figure 4A) compared to milk processed drug (Figure 4B) shows a decrease in the number of toxic components. We observed the formation of lipo-14-O-anisoylbikhaconine, benzoylmesaconine, and benzoylaconine that are distinctively present only in the processed drug sample and not present in the unprocessed drug. Compounds belonging to the less toxic and monoester diterpene alkaloids (MDA) category, viz. hokbusine b, bullatine B, talatizamine, ignavine, isodelphinine, and delgrandine, were also observed. The content of aconitine, mesaconitine and hypaconitine in the unprocessed drug calculated in terms of dry powder form was $11.310,9.680$ and $13.760 \mathrm{mg} / \mathrm{kg}$ which were found to be reduced to $1.050,1.964$ and $0.943 \mathrm{mg} / \mathrm{kg}$ respectively in the processed drug. This indicated that a 10-12 fold decrease in the content of selected DDA contents occurred in the processed sample (see Table 4). The milk filtrate obtained after treatment of the drug, (see Additional file 1: Figure S1-A of additional data files) was found to contain atisine, (-) salsolinol, senbusine, songoramine, senbusine- $\mathrm{C}$ and deltaline (the components belonging to the more toxic class of aconitum alkaloids) along with other less toxic compounds.

In the detoxification process of $A$. carmichaelii with cow milk, the unprocessed drug profile (see Figure 5A) shows presence of lesser number of components as compared to the processed drug (Figure 5B). The content of aconitine, mesaconitine and hypaconitine were found to be reduced from $16.265,15.305$ and $16.245 \mathrm{mg} / \mathrm{kg}$ to $2.078,1.047$ and $1.797 \mathrm{mg} / \mathrm{kg}$, respectively. An overall 8-15 fold decrease in the content of the marker alkaloids was observed as shown in Table 4. The milk filtrate was found to contain the toxic components like hypaconitine, aconitine, mesaconitine, beiwutine, atisine, carmichaelline, (-) salsolinol, and songoramine, as seen in Additional file 1: Figure S1-B of the additional data file. The formation of unknown compounds U1 and U5 along with lipo-14-O-anisoylbikhaconine, benzoylaconine, beiwutine and benzoylmesaconine was also evident in processed Aconitum carmichaelii (see Figure 5B).

Table 2 Results of precision studies

\begin{tabular}{|c|c|c|c|}
\hline Parameters & $\begin{array}{l}\text { Aconitine } \\
\text { (ng mL } \mathrm{mL}^{-1} \text { ) }\end{array}$ & $\begin{array}{c}\text { Mesaconitine } \\
\left.\text { (ng mL } \mathrm{mL}^{-1}\right)\end{array}$ & $\begin{array}{l}\text { Hypaconitine } \\
\text { (ng mL } \mathrm{mL}^{-1} \text { ) }\end{array}$ \\
\hline \multicolumn{4}{|l|}{ Interday precision } \\
\hline Content values ${ }^{* a}($ Mean \pm S. D.) & $4.372 \pm 0.001$ & $4.764 \pm 0.003$ & $4.523 \pm 0.004$ \\
\hline$\%$ RSD & 0.037 & 0.064 & 0.107 \\
\hline \multicolumn{4}{|l|}{ Intraday precision } \\
\hline Content values ${ }^{* b}($ Mean \pm S. D.) & $4.160 \pm 0.010$ & $4.608 \pm 0.011$ & $4.352 \pm 0.020$ \\
\hline$\%$ RSD & 0.243 & 0.249 & 0.477 \\
\hline
\end{tabular}

*a values for three replicate determinations; ${ }^{b}$ values for five replicate determinations data were collected. 
Table 3 Results of recovery studies

\begin{tabular}{|c|c|c|c|}
\hline Accuracy & $\begin{array}{c}\text { Aconitine } \\
* \text { Mean } \pm \text { S. D. }\end{array}$ & $\begin{array}{l}\text { Mesaconitine } \\
* \text { Mean } \pm \text { S. D. }\end{array}$ & $\begin{array}{l}\text { Hypaconitine } \\
{ }^{*} \text { Mean } \pm \text { S. D. }\end{array}$ \\
\hline \multicolumn{4}{|l|}{ Low level Spike (50\%) } \\
\hline Amount of standard added (ng) & 2.200 & 2.460 & 2.260 \\
\hline Amount of standard recovered (ng) & $2.313 \pm 0.012$ & $2.316 \pm 0.002$ & $2.203 \pm 0.004$ \\
\hline$\%$ Recovery & 105.150 & 94.174 & 97.516 \\
\hline \multicolumn{4}{|l|}{ Intermediate level Spike (100\%) } \\
\hline Amount of standard added (ng) & 4.440 & 4.920 & 4.520 \\
\hline Amount of standard recovered (ng) & $4.159 \pm 0.007$ & $5.326 \pm 0.013$ & $3.928 \pm 0.010$ \\
\hline$\%$ Recovery & 93.671 & 108.250 & 86.920 \\
\hline \multicolumn{4}{|l|}{ High level Spike (150\%) } \\
\hline Amount of standard added (ng) & 6.640 & 7.380 & 6.78 \\
\hline Amount of standard recovered (ng) & $6.573 \pm 0.005$ & $7.330 \pm 0.006$ & $6.474 \pm 0.004$ \\
\hline$\%$ Recovery & 98.992 & 99.322 & 95.500 \\
\hline Avg. Recovery & $99.271 \%$ & $100.582 \%$ & $93.312 \%$ \\
\hline RSD \% & 0.057 & 0.070 & 0.060 \\
\hline
\end{tabular}

*(n=3) for each of the values mentioned for the above determinations.

In the case of $A$. kusnezoffii, the unprocessed drug was found to contain fewer components as compared to the processed samples (see Figure 6A and $\mathrm{B}$ ). This indicates the possible formation of aconines and benzoylaconine products along with other non-toxic components due to hydrolysis. As observed in Additional file 1: Figure S1-C of the additional data file, the milk extract of Aconitum kusnezoffii contained (-) salosinol, mesaconitine, aconitine, hypaconitine, beiwutine and the unknown compound U5 in the unprocessed drug. In the processed drug (Figure 6B), benzoyl aconine, 14-O-veratoylneoline, isodelphinine, lipo-14-O-anisoylbikhaconine, aconifine, lycoctonine and bullatine $\mathrm{B}$ were found. The contents of aconitine, mesaconitine and hypaconitine decreased from 14.405, 14.150 and $18.135 \mathrm{mg} / \mathrm{kg}$ to $3.960,4.389$ and $1.720 \mathrm{mg} / \mathrm{kg}$, respectively, indicating an overall 4-8 fold decrease in the content of the alkaloidal components (see Table 4).

There are several reports which suggest that alkaloidal components are easily extracted into milk [38-40], and they are unstable at elevated temperatures [17]. Also, the $\mathrm{pH}$ of milk (ca. pH 6.5) that is acidic compared to plasma, leads to the transfer of basic compounds like plant alkaloids into the milk [41]. We suggest that affinity of alkaloids towards milk due to differences in the $\mathrm{pH}$ and their instability at elevated temperatures are the factors that support this ancient alchemical process and our experimental hypothesis for the use of cow milk in detoxification of aconitum roots.

\section{Comparison of samples treated with cow urine}

In the detoxification process with cow urine, it was observed that the unprocessed $\operatorname{drug}$ of $A$. heterophyllum (see Figure 4A) has comparatively fewer peaks than the processed drug (Figure $4 \mathrm{C}$ ) and the urine filtrate (Additional file 2: Figure S2-A of the additional data file). Although not as efficient as milk, cow urine could also essentially extract toxic components like (-) salsolinol, atisine, deltaline, mesaconitine, aconitine, songoramine, and benzoylaconine (as seen in Additional file 2: Figure S2-A of the additional data file). As shown in Figure 4C, processed $A$. heterophyllum contains the compounds benzoylmesaconine, anthranoyllcoctonine, lipo-14-O-anisoylbikhaconine and neojiangyouaconitine. The content of markers in the processed drug showed a 3-4 fold decrease from $11.310,9.680$ and $13.760 \mathrm{mg} / \mathrm{kg}$ to $4.700,2.127$ and $3.284 \mathrm{mg} / \mathrm{kg}$ for aconitine, mesaconitine and hypaconitine compared to the unprocessed drug (Table 4).

Compared with the LC-MS BPC profile of unprocessed A. carmichaelii (Figure 5A), the profile of urine filtrate and the processed drug, both showed a marked increase in number of components (Additional file 2: Figure S2-B and Figure $5 \mathrm{C}$ ). The urine filtrate was found to contain benzoylaconine, songorine, mesaconitine, beiwutine, hypaconitine, aconitine, 3-deoxyaconitine and carmichaelline. The processed drug was found to contain lipo-14-O-anisoylbikhaconine, aconifine, delbrusine, 14-O-anisoylneoline, and lycoctonine. A 3-4 fold reduction was observed in the initial concentration of the toxic components compared with the unprocessed drug (see Table 4). The contents of aconitine, mesaconitine and hypaconitine were found to decrease to 5.536, 3.518 and $4.405 \mathrm{mg} / \mathrm{kg}$, respectively.

In A. kusnezoffii, the unprocessed drug (Figure 6A) contains fewer components as compared to the urine 

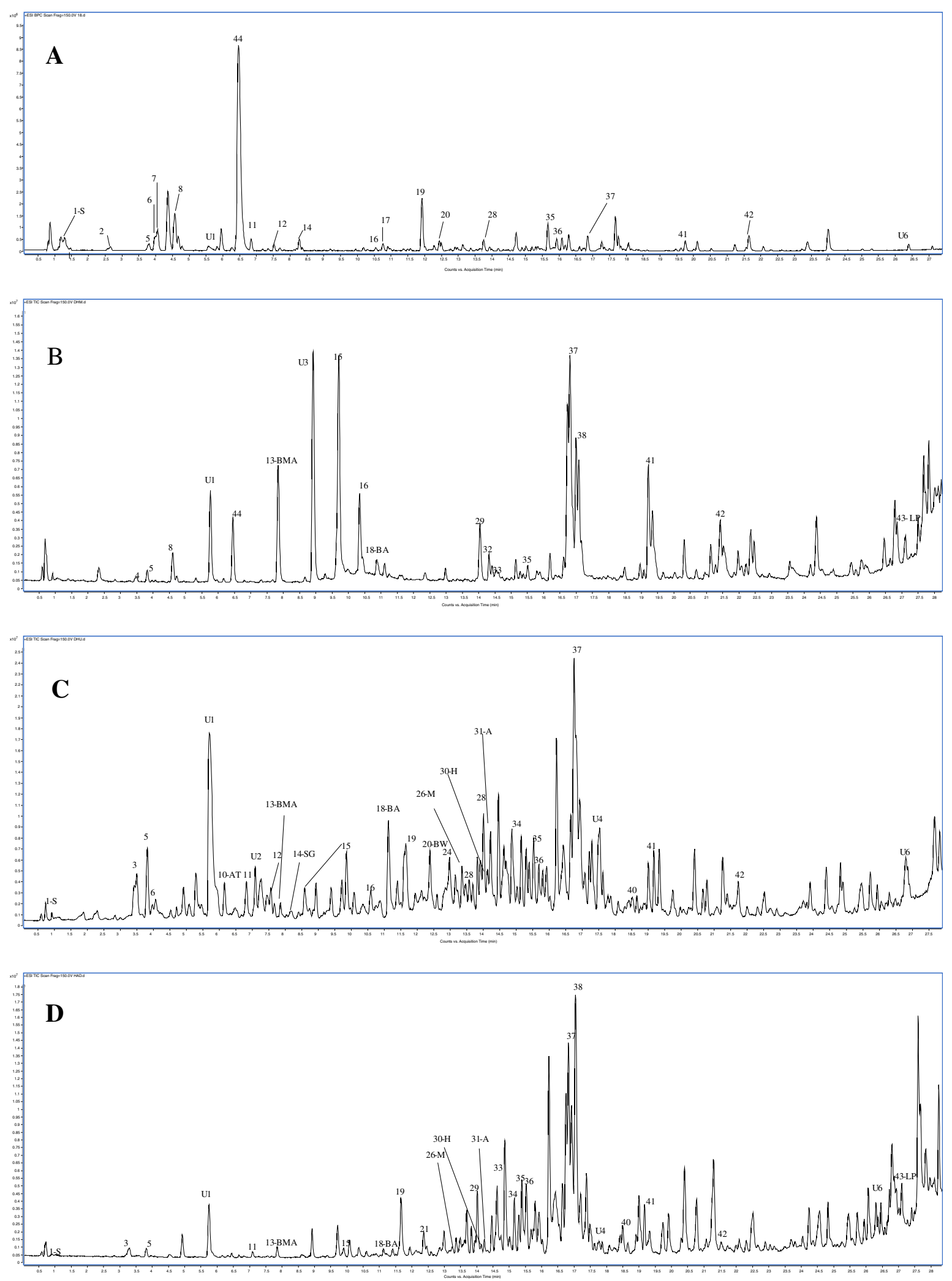

Figure 4 Representative LC-MS base peak chromatograms of roots of $A$. heterophyllum before and after processing (A) Unprocessed sample (B) Processed with cow milk (C) Processed with cow urine (D) Processed with water. Abbreviations used: AT- Atisine, BW- Beiwutine, BAbenzoylaconine, A- Aconitine, M-Mesaconitine, H-Hypaconitine, LP- Lipo-14-O-anisoylbikhaconine, S-(-) Salsolinol, SG-Songoramine, BMA- benzoylmesaconine. 

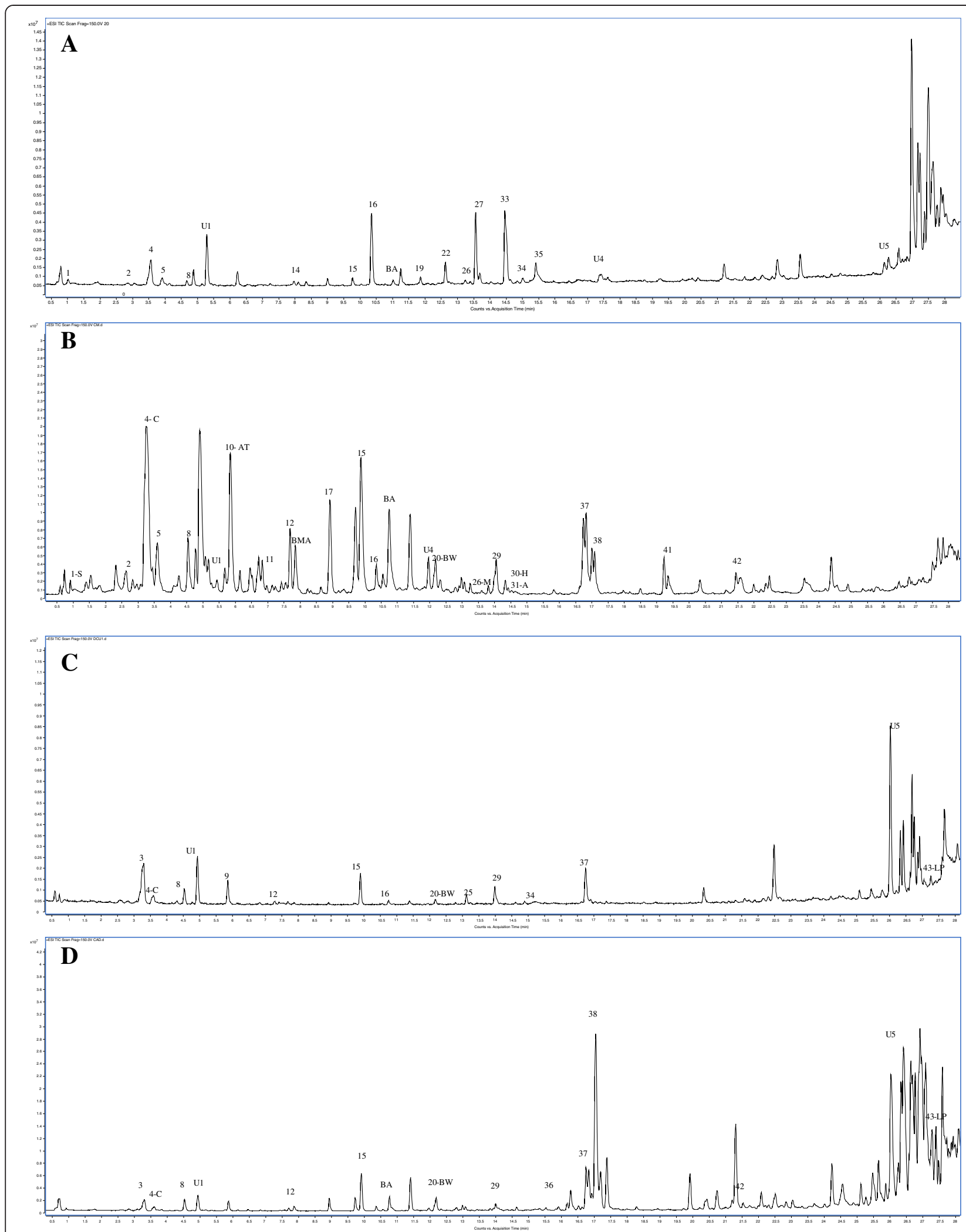

Figure 5 Representative LC-MS base peak chromatograms of roots of $A$. carmichaelii before and after processing (A) Unprocessed sample (B) Processed with cow milk (C) Processed with cow urine (D) Processed with water. Abbreviations used: AT- Atisine, BMA- Benzoylmesaconine, BA- Benzoylaconine, SB-Senbusine-A- Aconitine, H-Hypaconitine, LP-Lipo-14-O-anisoylbikhaconine, S-(-) Salsolinol, C-carmichaelline, BW-Beiwutine, M-Mesaconitine. 

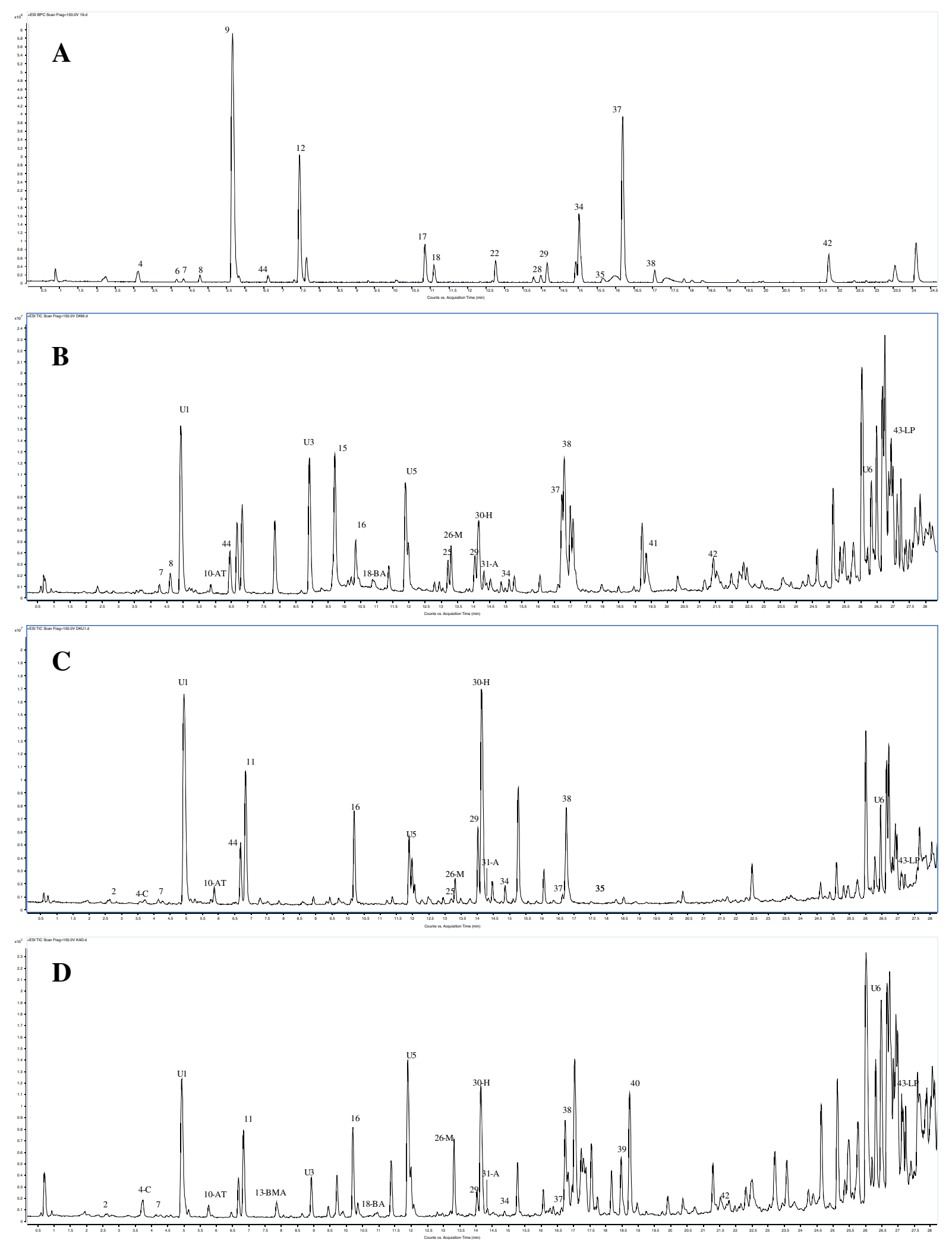

Figure 6 Representative LC-MS base peak chromatograms of roots of $A$. kusnezoffii before and after processing (A) Unprocessed sample (B) Drug boiled in cow milk (C) Processed with cow urine (D) Processed with water. Abbreviations used: S-(-) Salsolinol, AT- Atisine, SG-Songoramine, BA- Benzoylaconine, A- Aconitine, H-Hypaconitine, M-Mesaconitine, BW- Beiwutine, BMA-Benzoylmesaconine, LP- Lipo-14-O-anisoylbikhaconine. 
Table 4 Content of toxic alkaloids in various processed and unprocessed samples of Aconitum roots

\begin{tabular}{|c|c|c|c|}
\hline Sample & $\begin{array}{c}\text { Aconitine } \\
(\mathrm{mg} / \mathrm{kg}) \\
\text { *Mean } \pm \text { S. D. }\end{array}$ & $\begin{array}{l}\text { Mesaconitine } \\
(\mathrm{mg} / \mathrm{kg}) \\
\text { *Mean } \pm \text { S. D. }\end{array}$ & $\begin{array}{l}\text { Hypaconitine } \\
(\mathrm{mg} / \mathrm{kg}) \\
{ }^{*} \text { Mean } \pm \text { S. D. }\end{array}$ \\
\hline \multicolumn{4}{|l|}{ A. heterophyllum } \\
\hline Unprocessed drug material & $11.310 \pm 0.629$ & $9.680 \pm 0.327$ & $13.760 \pm 0.022$ \\
\hline Drug processed with Cow milk & $1.050 \pm 0.146$ & $1.964 \pm 0.504$ & $0.943 \pm 0.016$ \\
\hline Filtrate of cow milk decoction & $0.274 \pm 0.052$ & $1.085 \pm 0.62$ & $0.361 \pm 0.058$ \\
\hline Drug processed with Cow urine & $4.700 \pm 0.034$ & $2.127 \pm 0.433$ & $3.284 \pm 0.856$ \\
\hline Filtrate of cow urine extraction & $5.209 \pm 1.426$ & $2.985 \pm 0.798$ & $4.076 \pm 065$ \\
\hline Drug processed with water & $1.900 \pm 0.002$ & $0.962 \pm 0.275$ & $0.119 \pm 0.032$ \\
\hline Filtrate of aqueous decoction & $2.198 \pm 0.968$ & $1.086 \pm 0.724$ & $0.212 \pm 0.105$ \\
\hline \multicolumn{4}{|l|}{ A. carmichaelii } \\
\hline Unprocessed drug material & $16.265 \pm 0.082$ & $15.305 \pm 0.605$ & $16.245 \pm 0.538$ \\
\hline Drug processed with Cow milk & $2.078 \pm 0.002$ & $1.047 \pm 0.748$ & $1.797 \pm 0.049$ \\
\hline Filtrate of cow milk decoction & $4.284 \pm 0.440$ & $1.288 \pm 0.249$ & $1.039 \pm 0.138$ \\
\hline Drug processed with Cow urine & $5.536 \pm 0.008$ & $3.518 \pm 0.322$ & $4.405 \pm 0.122$ \\
\hline Filtrate of cow urine extraction & $1.361 \pm 0.688$ & $3.428 \pm 0.127$ & $6.177 \pm 1.720$ \\
\hline Drug processed with water & $1.150 \pm 0.445$ & $1.729 \pm 0.275$ & $2.829 \pm 0.007$ \\
\hline Filtrate of aqueous decoction & $2.615 \pm 0.578$ & $2.40 \pm 0.775$ & $3.174 \pm 0.583$ \\
\hline \multicolumn{4}{|l|}{ A. kusnezoffii } \\
\hline Unprocessed drug material & $14.405 \pm 0.386$ & $14.150 \pm 0.605$ & $18.135 \pm 0.229$ \\
\hline Drug processed with Cow milk & $3.960 \pm 0.088$ & $4.389 \pm 0.060$ & $1.720 \pm 0.069$ \\
\hline Filtrate of cow milk decoction & $7.817 \pm 1.707$ & $8.502 \pm 1.71$ & $13.658 \pm 4.21$ \\
\hline Drug processed with Cow urine & $11.125 \pm 0.101$ & $4.865 \pm 0.220$ & $3.088 \pm 0.053$ \\
\hline Filtrate of cow urine extraction & $2.258 \pm 0.231$ & $6.689 \pm 0.218$ & $3.840 \pm 0.33$ \\
\hline Drug processed with water & $2.050 \pm 0.056$ & $2.448 \pm 0.150$ & $1.067 \pm 0.070$ \\
\hline Filtrate of aqueous decoction & $4.947 \pm 1.749$ & $4.086 \pm 1.095$ & $2.863 \pm 0.817$ \\
\hline
\end{tabular}

*(n=3) for each of the values mentioned for the above determinations.

filtrate (Additional file 2: Figure S2-C of additional data file) and the processed drug (Figure 6C). The cow urine filtrate obtained after processing, shows the presence of benzoylaconine, hypaconitine, aconitine, beiwutine, and mesaconitine. The processed drug shows difference in the presence of new components such as lipo-14-O-anisoylbikhaconine, senbusine-C, and delphatine. The LCMS profile observations showed a 4-6 fold decrease in the content of toxic alkaloids, with decreased values of aconitine, mesaconitine and hypaconitine as 11.125, 4.8653 and $3.088 \mathrm{mg} / \mathrm{kg}$, respectively (see Table 4).

The ancient literature and modern scientific findings suggest that cow urine can enhance the potency and bioavailability of drugs, reduce toxicity and potentiate the efficacy of drugs without itself acting as a drug [42-52]. In our experiments, the cow urine used for processing was found to have $\mathrm{pH}$ 6.9. The acidic $\mathrm{pH}$ of the urine and exposure to heat through sunlight may be the possible reasons for the detoxification reaction of aconitum alkaloids.
Comparison of samples treated by aqueous decoction

The Chinese pharmacopeia states several methods for processing of aconite roots by treatment with mineral salt, steaming and decoction with water [7]. We selected the process of boiling with water for our study because water is the most easily and widely available solvent and because it is commonly used for detoxification of several other drugs. The TCM method was found to be the most effective method for detoxification as inferred from the overall decrease observed in the toxic alkaloid marker contents in comparison to the values obtained for the other two methods of Shodhana (see Table 4). For A. heterophyllum unprocessed drug, the results (see Figure 4A) clearly show that there is an effective extraction of components in the aqueous filtrate. This may be due to some hydrolytic reaction (Figure 4D). The components extracted in the aqueous filtrate are greater in number and more toxic in nature than the components present in the processed drug (Additional file 3: Figure S3-A of additional data file). Most of the components 
found in the aqueous filtrate, viz. atisine, beiwutine, deltaline, mesaconitine, (-) salsolinol, hypaconitine, aconitine and songoramine, are toxic. The processed drug contained the components anthranoyllcoctonine, neojiangyouaconitine, songorine, delgrandine, lipo-14-O-anisoylbikhaconine and the unknown components U1 and U5. There was a remarkable 10-12 fold decrease in the content of aconitine; mesaconitine and hypaconitine, with the processed drug containing 1.900, 0.962, and $0.119 \mathrm{mg} / \mathrm{kg}$ of the respective markers (see Table 4).

In case of A. carmichaelii, the unprocessed drug LCMS profile (Figure 5A) shows fewer components before processing. Upon processing, the aqueous filtrate shows the presence of the components benzoylmesaconine, benzoylaconine, beiwutine, mesaconitine, aconitine, carmichaelline, atisine and the unknown components U1 and U6 (as indicated in Additional file 4: Figure S3-B). The processed drug profile (Figure 5D), shows the presence of carmichaelline, beiwutine and non-toxic components lipo-14-O-anisoylbikhaconine, dihydroatisine, senbusine $B$, senbusine $C$ and the unknown components named U1 and U6. There was a 15-16 fold decrease in the toxic alkaloidal content of the unprocessed drug, with the values for aconitine, mesaconitine and hypaconitine obtained as $1.150,1.729$ and $2.829 \mathrm{mg} / \mathrm{kg}$, respectively.

Like the other two drugs, the unprocessed drug LCMS profile of Aconitum kusnezoffii (Figure 6A), has very few components as compared to the processed drug and the aqueous filtrate obtained from decoction. This suggests an active hydrolytic conversion of the DDA's to MDA's in the detoxification process. The aqueous filtrate (see Additional file 3: Figure S3-C of additional data file) was found to contain atisine, benzoylaconine, aconitine, mesaconitine and hypaconitine, which belong to the more toxic class of aconitine alkaloids. The processed drug, along with reduced content of benzoylaconine, benzoylmesaconine and (-) salsolinol, showed the presence of 14-O-veratoylneoline, hestisine, and lipo-14-O-anisoylbikhaconine (see Figure 6D). The aconitine, mesaconitine and hypaconitine contents were found to decrease to 2.050, 2.448 and $1.067 \mathrm{mg} / \mathrm{kg}$ respectively indicating an overall 7 - fold decrease in the toxic alkaloid content.

After an extensive literature survey of constituents reported in Aconitum species and after exclusion of components found in the blank controls of solvents used for processing, we found 5 unknown compounds whose identity was not confirmed. The molecular features of $\mathrm{m} / \mathrm{z}$ value, molecular formula and UV max absorption were obtained by UHPLC-Q-TOF/MS analysis. The unknown compound $U 1$ has retention time $\left(t_{R}\right) 5.32$ mins and $\mathrm{m} / \mathrm{z}$ value 453.273 . The molecular formula was found to be $\mathrm{C}_{24} \mathrm{H}_{39} \mathrm{NO}_{7}$. Compound $\mathrm{U} 2$, was found to exhibit a retention time $\left(t_{R}\right) 7.30 \mathrm{mins}$ and $\mathrm{m} / \mathrm{z}$ value 480.295 . The molecular formula was found to be $\mathrm{C}_{26} \mathrm{H}_{41} \mathrm{NO}_{7}$. Compound $\mathrm{U} 3$ was found to have $\mathrm{m} / \mathrm{z}$ value of 450.228 with retention time $\left(t_{R}\right) 9.10$ and with molecular formula as $\mathrm{C}_{27} \mathrm{H}_{31} \mathrm{NO}_{5}$. The unknown compound $\mathrm{U} 4$ had a retention time $\left(t_{R}\right)$ of $17.60 \mathrm{mins}$ and $\mathrm{m} / \mathrm{z}$ value of 628.349 . The molecular formula for $U 4$ was found to be $\mathrm{C}_{30} \mathrm{H}_{57} \mathrm{~N}_{15}$. Compound U5 was found to have molecular formula of $\mathrm{C}_{32} \mathrm{H}_{45} \mathrm{NO}_{10}$ with retention time $\left(\mathrm{t}_{\mathrm{R}}\right) 12.100 \mathrm{mins}$ and $\mathrm{m} / \mathrm{z}$ value 626.294. The compounds U4 and U5 have molecular weights closer to the reported diester and monoester alkaloids. Thus we infer that they may belong to the monoester group of alkaloids formed after hydrolysis, caused due to processing. Compound U6 was found to have a high molecular $\mathrm{m} / \mathrm{z}$ value of 850.570 with the molecular structure as $\mathrm{C}_{47} \mathrm{H}_{73} \mathrm{NO}_{11}$. This indicates that, U6 may possibly belong to the high molecular weight lipoid group of alkaloids, which is further substantiated by its delayed retention time $\left(t_{R}\right)$ of 26.50 mins. for elution. Due to lack of sufficient literature and reference compounds, the exact identity of the unknown compounds could not be established. Nevertheless, the molecular characteristics estimated from UHPLC-Q-TOF/MS analyses are shown in Additional file 4: Table S1 (additional data).

There are several animal based studies which report the lethal toxicity of unprocessed drug in comparison to the processed drug in which the toxicity is drastically reduced. Also several quantitative analysis methods report the estimation of increase in the hydrolysed products like aconine, hypaconine and mesaconine in the processed form of drug [53-60]. Hson-Mou and Paul have compiled several studies for toxicity of many drugs that include aconitum [61]. It states that in mice, when the toxicities $\left(\mathrm{LD}_{50}\right)$ of the processed pieces of Aconite by oral and intravenous injection were tested the values were found to be 17.42 and $3.516 \mathrm{~g} / \mathrm{kg}$ respectively. And overall, the toxicity level of the processed drug in comparison to the unprocessed raw drug was between 1/350 and $1 / 5$ times. For oral dosage the $\mathrm{LD}_{50}$ was higher than $100 \mathrm{~g} / \mathrm{kg}$. Furthermore, there are no studies that report the comparative detoxification studies of aconite by TCM and Ayurveda method and the above discussed reports further support the findings of our study.

\section{Experimental}

\section{Collection of plant material}

The dried unprocessed roots of $A$. heterophyllum were obtained from commercial Ayurvedic stores from Mumbai, India and the unprocessed roots of $A$. carmichaelii, and $A$. kusnezoffii were purchased from commercial herbal stores in China. The authentication of all the plant materials used for the study was carried out by Professor ZhongZhen Zhao and the voucher specimens were deposited in the Chinese Medicines Centre of Hong Kong Baptist 
University. Roots with varying sizes were collectively used for various processing methods.

\section{Chemicals and reagents}

Methanol and acetonitrile (HPLC grade) used as solvents for the mobile phase were obtained from E. Merck (Darmstadt, Germany). Formic acid (HPLC grade - purity 96.0\%) used as a modifier was purchased from Tedia Company Inc (U.S.A.). Ultra-pure water used in various procedures of the experiment was obtained from a Milli-Q water purification system (Millipore, Bedford, MA, U.S.A.). Standard aconitine, mesaconitine, and hypaconitine were obtained from Tauto Biotech Co. Ltd. Sanghai, China.

\section{Detoxification processes of samples}

All the three selected species of aconite roots were subjected to the traditional Shodhana and TCM methods of processing. The aim of the present work was to study the effect of traditional processing methods on the reduction of toxic contents of aconite. The factors like particle sizes of the drug material, processing times and shape of the roots, significantly affect the extraction of analytes. To specifically depict the traditional detoxification process and derive precise conclusions about the changes occurring in constituents due to such processing, we have used all the above mentioned parameters for the process as mentioned in the traditional records, and none of them were modified $[7,25]$. After the detoxification process all the dried processed forms of the drug were powdered (mesh size 2-8), subjected to extraction with chloroform and diluted with methanol prior to analysis.

Also, the processing practice by common people or traditional medicine practitioners would involve random selection of roots of varying shapes. This is a crucial aspect for a drug as aconitum where the toxicity varies not only based upon the size but also the shape of the roots. For instance, in the ancient TCM record "Origins of the Materia Medica" (Ben Cao Yuan Shi, published in 1612) it is mentioned that the roots of A. carmichaelii that have more number of projections and are large in size will be more potent as compared to those which have fewer projections [62]. We have found similar results in one of our unpublished works, where we have compared the toxic components of Aconitum roots of various sizes and shapes. Thus, to avoid any bias occurring due to particular shape, we have carried out random sampling of the roots for this study.

For Shodhana treatment with cow urine, the coarse powdered drug (mesh size 2-8) was kept immersed in cow urine in a tray and exposed to direct sunlight for 3 days. Every $5.0 \mathrm{~g}$ of sample was immersed in about $60.0 \mathrm{~mL}$ cow urine. For Shodhana with cow milk, $5.0 \mathrm{~g}$ of each of the drugs were hung in bags made of muslin cloth and placed in baths of boiling milk for 5 hours.

For the TCM method recorded in the Chinese pharmacopoeia, the aconitum roots were macerated in water for about 18 hours. After maceration, few roots were representatively cut to check that there was no hard core inside. The roots were soaked until there was no hard core observed inside after cutting [7]. The roots were then boiled in fresh water until there was no white core observed in the larger size roots. This process required approximately 6 hours in our experiments. The roots were then allowed to air dry, cut into slices and dried.

\section{Preparation of sample solutions}

The processed drugs were powdered to uniform particle size of (mesh size 2-8) for further extraction and analysis. About $0.5 \mathrm{~g}$ sample powder was accurately weighed and transferred into a $10-\mathrm{mL}$ centrifuge tubes. About $5.0 \mathrm{~mL}$ of chloroform was added and the mixture was sonicated for $30 \mathrm{~min}$, followed by centrifugation at $3000 \mathrm{rpm}$ for $10 \mathrm{~min}$. The obtained chloroform extracts were filtered through $0.45 \mu \mathrm{m}$ filters and diluted further with methanol to obtain appropriate concentrations for analysis.

\section{Preparation of standard solutions}

Stock solutions of aconitine, mesaconitine and hypaconitine were prepared individually in methanol (HPLC grade). Working solutions of standard compounds were prepared by appropriate dilutions of respective stock solutions to obtain concentration of $400 \mathrm{ng} \mathrm{mL}^{-1}$ each. Serial dilutions of mixed standard solutions of aconitine, mesaconitine and hypaconitine were prepared in the range $2-100 \mathrm{ng} \mathrm{mL}^{-1}$ for calibration curve estimation.

\section{Quantitative analysis by UHPLC-Q-TOF-MS}

Ultra-performance liquid chromatography was carried out using an Agilent 6540 accurate - mass Q-TOF LC/MS (Agilent Technologies, U.S.A.) [63,64]. Separation of components in the samples was performed at $20^{\circ} \mathrm{C}$, using a UPLC $\mathrm{C}_{18}$ analytical column (I.D. $1.7 \mu \mathrm{m}$, ACQUITY $\mathrm{UPLC}^{\circ} \mathrm{BEH}$, dimensions: $2.1 \mathrm{~mm} \times 100 \mathrm{~mm}$, Waters, U.S.A.), attached with a $\mathrm{C}_{18}$ pre-column $(2.1 \mathrm{~mm} \times$ $5 \mathrm{~mm}$, I.D. $1.7 \mu \mathrm{m}$, VanGuard TM BEH, Waters, U.S.A.).

The mobile phase consisted of a mixture of water (A) and acetonitrile (B), both containing $0.1 \%$ formic acid. The optimized linear gradient elution was as follows: 0$10 \mathrm{~min}, 5-25 \% \mathrm{~B} ; 10-25 \mathrm{~min}, 25-75 \% \mathrm{~B} ; 25-28 \mathrm{~min}$, $75-100 \% \mathrm{~B} ; 28-31 \mathrm{~min}, 100-100 \% \mathrm{~B} ; 31-31.1 \mathrm{~min}$, $100-5 \%$ B with 2.9 min of equilibrium time. The injection volume used for analysis was $2 \mu \mathrm{L}$. The flow rate was kept constant at $0.4 \mathrm{~mL} / \mathrm{min}$. The acquisition of mass spectra was done in positive mode by scanning from 110 to 1700 in mass to charge ratio $(\mathrm{m} / z)$. The operation parameters for MS analysis were as follows: 
dry gas $\left(\mathrm{N}_{2}\right)$ flow rate $6 \mathrm{~L} / \mathrm{min}$, nebulizer pressure $40 \mathrm{psi}$, dry gas temperature $300^{\circ} \mathrm{C}$, Vcap 4500 , fragmentor voltage $150 \mathrm{~V}$ and nozzle voltage $500 \mathrm{~V}$.

The contents of aconitine, mesaconitine and hypaconitine were estimated in the processed and unprocessed samples. The average values of triplicate estimations of the contents of marker compounds were calculated and expressed as their amounts in processed and unprocessed samples.

\section{Validation of developed analytical method}

The validation of the developed method was carried out in accordance with the ICH guidelines - Q2R1 (ICH, 2005). The parameters considered for validation were linearity, limit of detection (LOD) and limit of quantitation estimation (LOQ), accuracy (recovery studies), and precision (intraday, interday and repeatability) studies.

The linearity studies were carried out by 6 point calibration method with triplicate analysis at each selected concentration for all three standard compounds. Suitable concentrations were selected and analyzed in order to obtain a good correlation coefficient value $\left(r^{2} \geq 0.99\right)$.

The LOD and LOQ were estimated by analysis at several concentrations of analytes, diluted appropriately to estimate the lowest possible concentration that can be detected and quantitated with the optimized experimental conditions. The standard deviations of the responses and the slopes of the calibration curves were used to obtain the value for LOD and LOQ of each of the marker compounds.

Precision of the method was analyzed by three parameters, viz. interday-precision, intraday precision and repeatability studies. Repeatability studies were carried out by determinations of analytes in five injections of samples. Intraday precision was carried out by determination of analytes concentration in sample injections on the same day injected at five time intervals, namely, 0,2 , 4, 8 and 12 hrs. Interday precision was performed by determination of analytes in samples once a day for 3 consecutive days. The\% RSD for all the determinations included in precision studies were calculated.

The accuracy of the developed method was estimated by performing recovery studies at three different concentration levels in triplicate within the linear range of the analytes. The recovery of the known added amount of markers added to the samples with known concentrations of markers were calculated and expressed as percentages of recovery.

\section{Data analysis}

The analysis of data was carried out with Agilent Mass Hunter Workstation software-Qualitative Analysis (version B 4.00, Build 4.0.479.5, Service Pack 3, Agilent Technologies, Inc. 2011). The parameters adopted for analysis were: peaks with height $\geq 2000$ counts; extraction restricted retention time 1.0-25.0 $\mathrm{min}$, charge state considered was 1; peak spacing tolerance of $0.0025 \mathrm{~m} / \mathrm{z}$, plus $7.0 \mathrm{ppm}$; compound relative height $\geq 2.5 \%$, and absolute height $\geq 1500$ counts; for elements of $\mathrm{C}, \mathrm{H}, \mathrm{O}$, $\mathrm{N}$ from 3-60, 0-120, 0-30, 0-30 respectively for generating formulae. Results were indicated with the help of base peak chromatograms (BPC with $\mathrm{m} / \mathrm{z}$ range 150 950) for each sample analysed. The statistical data analysis was performed by Graph Pad INSTAT software (version 3.01).

\section{Conclusions}

In the present study, three detoxification strategies comprising of Shodhana treatment with cow milk and cow urine and TCM process of aqueous decoction were compared. The order of efficiencies of the three processes for detoxification can be stated as: Processing with water $>$ Shodhana with cow milk $>$ Shodhana with cow urine. From the study we can infer that all the three methods of detoxification compared in this study are efficient in detoxification. This is the first study to report comparative study on the traditional experiences of processing of Aconite roots between Ayurveda and TCM. Also, to the best of our knowledge, this is the first study to explore the chemical profile of aconitum roots after treating by two forms of Shodhana (an ancient Ayurveda detoxification process) and for quantitation of the toxic alkaloids before and after processing.

We have applied these ancient methods of detoxification from traditional systems of two different countries and substantiated their validity through comparative experimental evidence. The developed analysis method finds its distinction in being the first study to demonstrate the comparative quantitative analysis and method validation of Shodhana treated aconitum by using the advanced and sensitive technique UHPLC-Q-TOF-MS. An easy and effective detoxification process by use of readily available solvents like water, cow urine and cow milk is suggested, and the process can be carried out easily by the consumers themselves. The present study provides better understanding of the processing of herbal drugs and can contribute towards the convergence of the ancient wisdom from different geographical and scientific backgrounds, thus supporting the concept of globalization of herbal medicine.

\section{Additional files}

Additional file 1: Figure S1. Representative LC-MS base peak chromatograms of milk filtrate after Shodhana treatment of aconite roots (A) A. heterophyllum (B) A. carmichaelii (C) A. kusnezoffii (D) Cow milk filtrate used as control. Abbreviations used: S-(-) Salsolinol, AT- Atisine, BA- Benzoylaconine, BMA-Benzoylmesaconine, SG- Songoramine, BW- 
Beiwutine, M-Mesaconitine, BW- Beiwutine , C- carmichaelline, LP- Lipo-14O-anisoylbikhaconine, SBC- Senbusine-C, A- Aconitine, H- Hypaconitine.

Additional file 2: Figure S2. Representative LC-MS base peak chromatograms of cow urine filtrate after Shodhana treatment of aconite roots (A) A. heterophyllum (B) A. carmichaelii (C) A. kusnezoffii (D) Cow urine used as control. Abbreviations used: C-carmichaelline, AT- Atisine, BA- Benzoylaconine, BW- Beiwutine, M-Mesaconitine, A- Aconitine, SB- Senbusine-C, SG- Songoramine, H- Hypaconitine.

Additional file 3: Figure S3. Representative LC-MS base peak chromatograms of aqueous filtrate after TCM treatment of aconite roots (A) A. heterophyllum (B) A. carmichaelii (C) A. kusnezoffii (D) Water used as control. Abbreviations used: S-(-) Salsolinol, AT- Atisine, BA- Benzoylaconine, BW- Beiwutine, M-Mesaconitine, A- Aconitine, H-Hypaconitine, BMABenzoylmesaconine, LP- Lipo-14-O-anisoylbikhaconine, SB- Senbusine - B.

Additional file 4: Table S1. Data for peaks of various constituents identified in the three selected Aconitum species. Footnote: Key: U1-U6 are the unknown constituents detected in various samples of selected Aconitum species.

Additional file 5: Table S2. List of molecular features of constituents present in the filtrate of cow milk and cow urine used for extraction of aconitum samples.

Additional file 6: Figure S5. Representation of the mechanism of formation of MDA compounds from DDA components of Aconitum alkaloids by successive loss of chemical groups and respective changes in $m / z$ values.

Additional file 7: Figure S4. Representative LC-MS-ESI scan spectra of various filtrates obtained after processing A. carmichaelii for depicting conversion of DDA compounds to MDA. (A) Unprocessed drug (B) Filtrate obtained after extraction with Cow urine (C) Filtrate obtained after extraction with Cow milk (D) Filtrate obtained after extraction with water. The MDA components and hydrolyzed products formed from DDA compounds are indicated with a red asterisk (*) symbol.

\section{Competing interests}

The authors declare that they have no competing interests.

\section{Authors' contributions}

YJ has carried out the experiments for the study, collected the data and analysed them and has written the manuscript. ZZ and ZL have been significantly involved by contributing their intellectual content for the research work, analyzing the results and correcting the manuscript accordingly. $\mathrm{HC}$ and PY have made their intellectual contributions in revising the manuscripts with their knowledgeable suggestions. The final manuscript has been read and approved by all the authors.

\section{Acknowledgements}

The authors are thankful to Mr. Alan Ho from the School of Chinese Medicine, Hong Kong Baptist University for his kind technical support. This work was supported by the National Natural Science Foundation of the People's Republic of China (Project No. 81173495).

\section{Author details}

'School of Chinese Medicine, Hong Kong Baptist University, Kowloon, Hong Kong Special Administrative Region, P. R. China. Institute of Medicinal Plant Development, Peking Union Medical College and Chinese Academy of Medical Sciences, Haidian District, Beijing, People's Republic of China.

Received: 2 April 2013 Accepted: 10 October 2013

Published: 25 October 2013

\section{References}

1. Mishra SN: Rasendra chintamani. India: Chaukhamba Orientalia; 2000

2. Heiner F: The flagship remedy of Chinese medicine: reflections on the toxicity and safety of aconite. Am J Chin Med 2012, 100:36-41.

3. Liangqian L, Kadota Y: Aconitum L. In Flora of china. Edited by Wu ZY Raven PH. Missouri Botanical Garden, Beijing/St. Louis: Science Press; 2001:149.

4. Anonymous: Wealth of India: Raw materials. New Delhi: CSIR; 1979.
5. Ministry of Health and Family Welfare: The ayurvedic formulary of India. New Delhi: The Controller of Publication; 1977.

6. Ministry of Health and Family Welfare: The ayurvedic pharmacopoeia of India. Delhi: The Controller of Publication; 1987.

7. Chinese Pharmacopoeia Commission: The pharmacopoeia of the People's republic of china (English edition). Beijing, China: China Medical Science Press; 2010.

8. Suzuki Y, Oyama A, Ishige A, Isono T, Asami A, Ikeda Y, Noguchi M, Omiya Y: Antinociceptive mechanism of the aconitine alkaloids mesaconitine and benzoylmesaconine. Planta Med 1994, 60:391-394.

9. Chan TY: Causes and prevention of herb-induced aconite poisonins in Asia. Hum Exp Toxicol 2011, 30:2023-2026.

10. Bisset NG: Arrow poisons in china. Part II. Aconitum-botany, chemistry, and pharmacology. J Ethnopharmacol 1981, 4:247-336.

11. Chan TY: Aconite poisoning following the percutaneous absorption of aconitum alkaloids. Forensic Sci Int 2012, 223:25-27.

12. Sharma PV: Caraka samhita (English translation). Varanasi, India: Chowkhamba orientalia; 2005.

13. Dhamanakar PV: Ayurvediya aushadhikarana. Mumbai, India: Dhootpapeshwar Prakashan; 1964

14. Belge RS, Belge AR: Ayurvedic shodhana treatments and their applied aspect with special reference to loha. IOSR - J Pharm Biol Sci 2012, 2:45-49.

15. Mishra LC: Scientific basis for ayurvedic therapies. Washington, DC: CRC Press; 2004.

16. Shah RK, Kenjale RD, Shah DP, Sathaye S, Kaur H: Evaluation of cardiotoxicity of shodhit and ashodhit samples of aconite root. Int J Pharmacol Biol Sci 2010, 4:65-68.

17. Judith S, Ming Z, Sonja P, Brigitte K: Aconitum in traditional Chinese medicine - a valuable drug or an unpredictable risk? J Ethnopharmacol 2009, 126:18-30.

18. Murayama M, Mori T, Bando H, Amiya T: Studies on the constituents of aconitum species IX. The pharmacological properties of pyro-type aconitine alkaloids, components of processed aconite powder 'kakobushi-matsu': analgesic, anti-inflammatory and acute toxic activities. J Ethnopharmacol 1991, 35:159-164.

19. Lei F: Compiled by Shang ZJ, Lei gong Pao Zhi Lun. Hefei: Anhui Science and Technology Press; 1991.

20. Zhang Z, Ye F, Wiseman W, Mitchell C, Feng Y: Shang Han Lun (on cold damage): translation and commentaries. Brookline: Paradigm Publications; 1999

21. Misra BS, Shastri KA, Lochan K, Choudhary AK: Bhaisajyaratnavali of govinda dasji. Varanasi, India: Chaukhamba Sanskrit Bhawan; 2006.

22. Singh RS, Singh $L B$, Bose $R$, Sen SP: Experimental studies on sodhana of aconite. Ancient Sci Life 1981, 1:106-109.

23. Zhao Z, Liang Z, Chan K, Lu G, Lee EL, Chen H, Li L: A unique issue in the standardization of Chinese materia medica: processing. Planta Med 2010, 76:1975-1986.

24. Tang W, Eisenbrand G: Chinese drugs of plant origin. Berlin-Heidelberg: Springer Verlag; 1992.

25. Sarkar PK, Prajapati PK, Shukla VJ, Ravishankar B: Effect of shodhana treatment on chronic toxicity and recovery of aconite. Toxicol Int 2012, 19:35-41.

26. Tong P, Wu C, Wang X, Hu H, Jin H, Li C, Zhu Y, Shan L, Xiao L: Development and assessment of a complete detoxication strategy for fuzi (lateral root of aconitum carmichaelii) and its application in rheumatoid arthritis therapy. J Ethnopharmacol 2013, 146:562-571.

27. Tan G, Lou Z, Jing J, Li W, Zhu Z, Zhao L, Zhang G, Chai Y: Screening and analysis of aconitum alkaloids and their metabolites in rat urine after oral administration of aconite roots extract using LC-TOF-MS based metabolomics. Biomed Chromatogr 2011, 25:1343-1351.

28. Lu G, Dong Z, Wang Q, Qian G, Huang W, Jiang Z, Leung KS, Zhao Z: Toxicity assessment of nine types of decoction pieces from the daughter root of aconitum carmichaelii (fuzi) based on the chemical analysis of their diester diterpenoid alkaloids. Planta Med 2010, 76:825-830.

29. Yue H, Pi Z, Song F, Liu Z, Cai Z, Liu S: Studies on the aconitine-type alkaloids in the roots of aconitum carmichaelii debx. By HPLC/ESIMS/MS (n). Talanta 2009, 77:1800-1807.

30. Yue H, Pi ZF, Li HL, Song FR, Liu ZQ, Liu SY: Studies on the stability of diester-diterpenoid alkaloids from the genus aconitum L. By high performance liquid chromatography combined with electrospray ionisation tandem mass spectrometry (HPLC/ESI/MSn). Phytochem Anal 2008, 19:141-147. 
31. Jiang ZH, Xie $Y$, Zhou H, Wang JR, Liu ZQ, Wong YF, Cai X, Xu HX, Liu L: Quantification of aconitum alkaloids in aconite roots by a modified RP-HPLC method. Phytochem Anal 2005, 16:415-421.

32. Chen JH, Lee CY, Liau BC, Lee MR, Jong TT, Chiang ST: Determination of aconitine-type alkaloids as markers in fuzi (aconitum carmichaelii) by LC/(+)ESI/MS3. J. Pharmaceut. Biomed Anal 2008, 48:1105-1111.

33. Csupor D, Forgo P, Wenzig EM, Bauer R, Hohmann J: Bisnorditerpene, norditerpene and lipo-alkaloids from aconitum toxicum. J Nat Prod 2008 71:1779-1782

34. $\mathrm{ICH}$ : Validation of analytical procedures (Q2 R1): text and methodology - ICH harmonised tripartite guideline. Geneva: ICH Steering Committee; 2005.

35. Atta-ur-Rahman, Choudhary MI: Diterpenoid and steroidal alkaloids. Nat Prod Rep 1999, 16:619-635.

36. Liu W, Pi Z, Wang X, Song F, Liu S: HPLC/ESI-MSn and ESI-MS studies on the aconitum alkaloids in three Chinese medicinal herbs. J Sep Sci 2010, 33:2898-2906.

37. Liu XX, Jian XX, Cai XF, Chao RB, Chen $Q H$, Chen DL, Wang XL, Wang FP: Cardioactive C19-diterpenoid alkaloids from the lateral roots of aconitum carmichaelii "Fu Zi". Chem Pharm Bull 2012, 60:144-149.

38. Dickinson JO: Release of pyrrolizidine alkaloids into milk. Proc West Pharmacol Soc 1980, 23:377-379.

39. Dickinson JO, Cooke MP, King RR, Mohamed PA: Milk transfer of pyrrolizidine alkaloids in cattle. J Am Vet Med Assoc 1976, 169:1192-1196.

40. Keith AL, Sufian A: Bad Bug book - foodborne pathogenic microorganisms and natural toxins. Maryland: U.S. Food and Drug Administration; 2012.

41. Panter KE, James LF: Natural plant toxicants in milk: a review. J Anim Sci 1990, 68:892-904.

42. Pandey GS, Chunekar KC: Bhav prakash nighantu (Indian materia medica) of Sri bhavamisra (c. 1600-1600 AD) - Ath mutravargh. Varanasi, India: Chaukhamba Bharati Academy; 2009.

43. Shukla AV, Tripathi RD: Caraka samhita of agnivesh. Delhi, India: Chaukhamba Sanskrit Pratishthan; 1997.

44. Bhadauria H: Cow urine- a magical therapy. Int J Cow Sci 2002, 1:32-36.

45. Randhawa GK: Cow urine distillate as bioenhancer. J Ayur Integ Med 2010 1:240-241

46. Prashith TR, Nishanth BC, Praveen SV, Kamal D, Sandeep M, Megharaj HK Cow urine concentrate: a potent agent with antimicrobial and anthelmintic activity. J Pharm Res 2010, 3:1025-1027.

47. Chauhan RS: Panchagavya therapy (Cow pathy) - current status and future directions. Indian Co 2004, 1:3-7.

48. Jain NK, Gupta VB, Garg R, Silawat N: Efficacy of cow urine therapy on various cancer patients in mandsaur district, India: a survey. Int $J$ Green Pharm 2010, 4:29-35.

49. Chawla PC: Risorine - a novel CSIR drug curtails TB treatment. CSIR News 2010, 60:52.

50. Ganaie JA, Shrivastava VK: Effects of gonadotropin releasing hormone conjugate immunization and bioenhancing role of kamdhenu ark on estrous cycle, serum Estradiol and progesterone levels in female Mus musculus. Iran J Reprod Med 2010, 8:70-75.

51. Khanuja SP, Kumar S, Shasany AK, Arya JS, Darokar MP, Singh M, Sinha P, Awasthi S, Gupta SC, Gupta VK, Gupta MM, Verma RK, Agarwal S, Mansinghka SB, Dawle SH: Use of bioactive fraction from cow urine distillate ('go-mutra') as a bio-enhancer of anti-infective, anti-cancer agents and nutrients. United States: USPTO; 2005. US patent no. 6896907.

52. Khan A, Srivastava $V$ : Antitoxic and bioenhancing role of kamdhenu ark (Cow urine distillate) on fertility rate of male mice (mus musculus) affected by cadmium chloride toxicity. Int J Cow Sci 2005, 1:43-46.

53. Huang QA, Zhang YM, He Y, Lu J, Lin RC: Studies on hydrolysis of aconitine. China J Chin Mat Med 2007, 32:2143-2145.

54. Sun WJ: Quantitative determination of total alkaloids and aconitine in the root of aconitum carmichaeli and aconitum [in Chinese]. Chung Yao Tung Pao 1984, 9:125-127.

55. Cao H: Determination of aconitine in wutou and related herbal drugs (roots of aconitum) and their processed products in Hong Kong market [in Chinese]. Chung-Kuo Chung Yao Tsa Chih 1993, 18:279-281. 318.

56. Chan TYK: Aconite poisoning. Clin Toxicol 2009, 47:279-285.

57. Ameri $A$ : The effects of aconitum alkaloids on the central nervous system. Prog Neurobiol 1998, 56:211-235.

58. Mizugaki M, Ito K: Aconite toxins. In Drugs and poisons in humans - a handbook of practical analysis. Edited by Suzuki O, Watanabe K. New York: Springer Verlag; 2005.
59. The Compile Commission of Zhonghua Bencao: Zhonghua Bencao. Shanghai: Shanghai Science and Technology Press; 1999. Shanghai.

60. Chan T, Tomlinson B, Tse L, Chan L, Chan W, Critchley J: Aconitine poisoning due to Chinese herbal medicines: a review. Vet Hum Toxicol 1994, 36:452-455.

61. Hson-Mou C, Paul PHB: Pharmacology and applications of Chinese materia medica. Singapore: World Scientific Publishing Ltd.; 2001.

62. Li ZL: Origins of the materia medica (Ben Cao Yuan Shi). Beijing, China: People's Medical Publishing House; 2007.

63. Hu R, Zhao J, Qi L, Li P, Jing S, Li H: Structural characterization and identification of C19- and C20-diterpenoid alkaloids in roots of aconitum carmichaeli by rapid-resolution liquid chromatography coupled with time-of-flight mass spectrometry. Rapid Commun Mass Spectrom 2009, 23:1619-1635.

64. Li SL, Zhang H, Liu X, Zhao ZL, Chen SL, Wang ZT, Xu HX: Rapid determination of yunaconitine and related alkaloids in aconites and aconite-containing drugs by ultra high-performance liquid chromatography-tandem mass spectrometry. Biomed Chromatogr 2012, 26:1567-1574.

doi:10.1186/1752-153X-7-169

Cite this article as: Jaiswal et al:: A comparative study on the traditional Indian Shodhana and Chinese processing methods for aconite roots by characterization and determination of the major components. Chemistry Central Journal 2013 7:169.

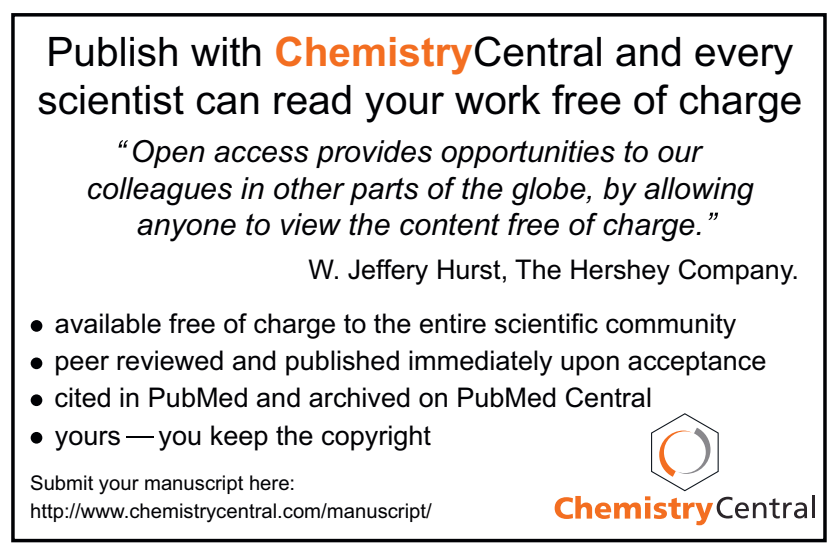

